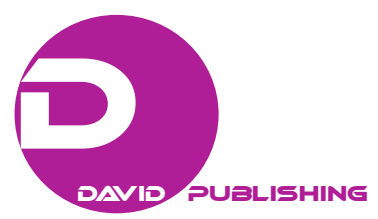

\title{
China as Culture
}

\author{
Kuang-ming Wu \\ University of Wisconsin-Oshkosh, USA
}

\begin{abstract}
This essay presents my bird's eye view of Chinese culture, under three headings. One, culture is the way of living. Two, our way of living is expressed in our four modes of thinking, as conspicuously exhibited by Chinese culture. Three, "these Chinese thinking-modes" share a goal with the West. Their common goal of interculture inter-enriches. "Inter-" implicates the world as not one-cultural but two-cultural, East and West, represented by China actual and the USA in logical analysis.
\end{abstract}

Keywords: body, concrete, stories, music, time logic

\section{One: Culture}

A culture covers a vast territory. Chinese culture is seen in Chinese continent, Korea, Japan, Taiwan, Southeast Asia, and even total Asia (India is influenced by Chinese culture), to compose the East. There was once even a movement called "Boston Confucianism". The East of Chinese culture adores Confucius, as the USA covers the Great Britain and Canada and virtually all the English-speaking world, where Shakespeare is universally admired. And you and I realize how vast the East typified by China is now, and how vast also the English-speaking world is today.

In all this, "culture" means a specific style of living. Culture is the lifeworld peculiar to that specific culture, differing from a different culture, which composes a distinctively different lifestyle. You enter a particular cultural world, and you even smell the distinctive fragrance of that distinctive lifeworld. A totally novel world looms so raw and large to your face in front of you, and nothing can be said about it.

And then you yourself in turn would be noticed as peculiar, and people there in that culture even explicitly criticize your hair style, your strange way of dressing yourself, and even your strange accent even though they understand what you mean in what you say. A new culture is a strange world where things are strange to you as you are strange to people in it. Xenophobia could easily erupt to invite tragic conflicts of all sorts, all so strange and unexpected. God knows how many battles big and small have erupted simply because of "new cultures" encountered, quite unpleasantly, as we are all birds of a feather, to flock together.

In short, culture as a way of living can be typified as a shared way of thinking among people within that specific culture. Cultural thinking is the propensity to think of things in a specific way or ways, rather than any other way. Culture is equivalent to the specific collection of peculiar modes of thinking. Culture is thinking mode or modes specific to a specific culture.

Thus it is important to specify a collection of modes of thinking in order to understand a culture, as understanding culture is as crucial as understanding a specific group of people. To understand people, we must

Kuang-ming Wu, Ph.D. Yale, Rosebush University Professor in Philosophy emeritus; Philosophy Department, University of Wisconsin-Oshkosh, USA. 
understand their culture. Now we consider Chinese culture in detail, as four modes of thinking under time logic in "wu wei" that is no-do.

\section{Two: Thinking}

\section{The West and the East}

The modes of thinking in the West, typified by the USA, are objectivity and management, as well as logical classification and analytical clarity. The West loves to settle things and affairs neatly, as if they were all already dead and the West is concocting their obituaries. The West is so much proud of its neat ways of thinking, and so much in love with them so clean, that the West takes its logical objectivity as the sole thinking-mode in the whole world.

The West has been totally unaware that the world has another different way of thinking entirely different from the West's logic and objectivity. Such logical objectivity is neat and set, toward which the West strives, by abstraction from bothersome complex actuality. Logical objectivity is abstract, out of this mundane dusty world. Or is the Western pride due to its unwillingness to admit the existence of its alternative way of thinking, existential and actual?

In any case, there has been in existence for countless centuries an alternative way of thinking of the world, an alternative to Western abstract neat way. It is the Chinese way in the East. It is thinking-alive, not thinking-dead. Since being alive tends to be vague and vacillating, this thinking-alive is rather complex, though quite actual and real, and easy to practice and understand, never abstruse and abstract as analytical logic that requires years of studying mathematical logic.

Chinese modes of thinking look strange and peculiar to the Western neat abstract thinking. Chinese thinking-modes are no less than four in number, to wit, body thinking-mode, concrete thinking, story thinking, and music thinking. These modes of thinking are cited in the order of intimacy, from our immediate body to cosmic music. They are all subsumable under time logic. Explanations are in order.

\section{Body Thinking Mode}

To begin, it strikes us immediately that all Chinese sayings are body-expressed. Chinese literature is bodily moving so beautiful heartfelt. This is a surprise to us who are accustomed to logical abstract statements in the West. But of course, no person is without her body, and she naturally expresses herself in body thinking in body language, a natural extension of which is body-sayings expressing body-thinking.

This body thinking in body-writing is the inevitable way in which Chinese literature directly hits the reader in the guts, as she read with her body, for there is no other way. Of course, there is no other way to read than to think and read within our body. But the West in its proud abstract body-less thinking- “abstract” abstracts us from our basic body—proudly "sees from nowhere” (Nagel, 1989) ${ }^{1}$ in particular at all. Western thinking is abstract, and without a body, and so it is universal indifferent to concrete places.

Is not such abstract theoretical thinking a ghostly thinking so aberrant? Is not Western thinking a thinking of the ghost town? But we are so sadly accustomed to such body-less thinking that we think of such thinking as no longer strangely ghostly. We have been brainwashed, by being abstracted from our basic concrete body. Our body is the prime example of how much we are anchored in the concrete. Robbed of the basic concrete, we are no longer alive.

\footnotetext{
${ }^{1}$ Analytical thinker Thomas Nagel published a book with this title, from Oxford University Press, 1989.
} 
Still, to think of it, our body is alive as we are, and anything alive thinks, and so our body thinks. Nothing is more natural than that our lived body thinks. If we think it strange that our body is just physical, and physical body should never think yet it thinks, it is because we think of "body" as merely physical and things physical do not think, then such our thinking comes from taking body as merely physical, and such taking of body as merely physical is due to abstracting our natural body from lived-body into mere physical body. We think so due to being brainwashed by Western abstract thinking. Chinese way of thinking, in body thinking, comes to rescue us from the Western ghostly abstraction (Wu, 1997). ${ }^{2}$

In any case, our body-as-thinking as concrete naturally reminds us that our thinking is always concrete thinking. Thus it is that our body thinking naturally guides us to our next concrete thinking that is body-thinking generalized.

\section{Concrete Thinking Mode}

We now go into the second thinking-mode, "concrete thinking”. As our body seeing is sensible, and being sensible is to exist as thinking, so we are alive thinking concretely, ever. To be body-alive is to think concretely. Body thinking is "concrete thinking". Now, logical analyst would at once object, saying, "Concrete thinking is a contradiction, for things concrete are what is thought about and not thinking, so concrete thinking is not-thinking thinking, an obvious contradiction”. This is a quibble of abstract thinking idle and useless, and diverting us away from our main road of consideration. Three responses at least are ready to hand.

One, the abstract is abstracted from the concrete. The abstract is senseless without referring to the concrete from which "abstract" is abstracted. And so, the very meaning of the abstract depends on the concrete to obtain. Two, the abstract is abstracted from the concrete so as to reach the concrete. The abstract is a byway toward the concrete. The abstract is an airplane taking off from the concrete solid ground to land on the concrete solid ground. Three, in fact, it is the concrete itself that takes off to land, all in the concrete. The abstract simply describes such movement of the concrete itself.

Still, the logical analyst persists, saying, "What a thing is obtains by objective observation from outside. External observation is precisely abstract thinking away from the concrete. Abstract thinking shapes the concrete". Concrete thinking would respond, saying, "All thinking is performed by the self ever concrete and intimate. No self, no thinking whatever”.

What this self is reveals itself to the self absent (亡), mindedly (心), self-forgotten (自忘). Objectivity of observation thus obtains while the subjectivity of the self stays to continue thinking. Concrete thinking remains, happily supporting all thinking on all things. Concrete thinking rules supreme over things, without which nothing whatever would exist at all. Concrete thinking supreme is essential, constant, and logically consistent. There is absolutely nothing contradictory about concrete thinking. On the contrary, concrete thinking is totally existential-intimate, as the intimate self is essential to all thinking whatever, on which anything whatever depends to exist. Does this fact surprise us? Surprise or not, it is simply a natural fact. As George Berkeley said, to be is to be perceived. To perceive is to think. And so, to be is to be thought about. I think, therefore things exist. Concrete thinking makes things to exist. Thinking is as personal and concrete as it is creative of the whole cosmos. Wow!

\footnotetext{
${ }^{2}$ My On Chinese Body Thinking: A Cultural Hermeneutic, Leiden: Brill, 1997, conducted dialogues divergent and then convergent between Chinese body (thinking) and M. Merleau-Ponty's “flesh” that is halfway between mind and substance. It was fun.
} 
Still, amazingly, China has been routinely performing such essential-existential concrete-thinking so intimate and so cosmic, for countless centuries since time immemorial. In fact, the Chinese people have been so routinely thinking concrete thinking that the phrase "concrete thinking" cannot be found in the usual Chinese vocabulary. We have had to concoct such strange phrase to describe Chinese thinking as distinctively Chinese.

We have two surprises here, then: One, China has been routinely thinking concrete thinking that no Western thinker does, and two, China has no such phrase "concrete thinking”. In all this, concrete thinking is irresistibly concrete, personal, cosmic, and intimate and ubiquitous. In the beginning is intimate concrete thinking that continues creating the world to complete the world to conclude the world. "Surprising concrete thinking so intimate and so personal” both begins and ends the whole world ( $\mathrm{Wu}, 2018 \mathrm{a}){ }^{3}$

\section{Story Thinking Mode}

And now, closely following concrete thinking, the third mode of thinking in China comes, to wit, "story thinking". Concrete thinking is story thinking. Story thinking answers the question: "How do we think concrete thinking?” Story thinking innately performs itself by telling stories. We are born storytellers. Each person is a walking autobiography, ever ready to tumble out telling of one's own life-story. But innate and ubiquitous storytelling may not be story-thinking as China performs. An explanation is in order.

Storytelling is so ubiquitous that even the analytical thinker Richard Rorty cites so many thinkers in the West telling stories to persuade the reader on how attractive their arguments are (Huang, 2009, pp. 279-280). But telling stories to strengthen an already existing argument is one thing. Telling stories to be guided into new thinking by those unexpected stories is quite another. The latter sort of storytelling is story thinking (Wu, 2011). ${ }^{4}$ The West tells stories but thinks no story-thinking. Few Western thinkers think story thinking, perhaps because they take such guide by story-thinking as beneath the "dignity of thinking".

It does not matter at all, for this exciting reason. By nature, our human body expands. As I am bodily alive, so you become bodily alive. Such body thinking is the Confucian family-principle. The Great Learning explicates its body-family expansion stage by stage. The Doctrine of the Mean then comes along to notice that such body-expansion is immediate and ubiquitous. Body thinking in this way tells stories in story thinking. Our body alive flows all over as one identical body-flow throughout Heaven and Earth (Mencious 7A13).

Now Taoism takes over. Our body thinking in concrete story thinking resoundingly tells us of even the torso-less skull ever alive, forever bodily enjoying embodied making of seasons round and around, together with Heaven and Earth (Chuang Tzu, Chapter 18). Human body alive beyond life and beyond death is one body with the vast cosmos, personal and ubiquitous, continually chanting the one-bodied joys of the entire universe. Such is Chinese culture alive expanding body thinking in concrete thinking of story thinking, in sheer joys of music thinking. It is a fool who does not drawn excited at this cosmic panorama so personal. Beware, the West so carefully dull!

\section{Music Thinking Mode}

Now, fourth and finally, from all these three thinking-modes, body, concrete, and story, "music thinking” naturally results to round them up and to beautify them all sonorously. As joy chants music, so self-love accompanies joy. And so, self-love is inherently music thinking. As each person loves her self, bodily concrete

\footnotetext{
${ }^{3}$ I combined concrete thinking with story thinking in my Concrete Thinking Story-Embodied as Joy (with Ruth Chao), Houston, TX: Studium Press, 2018.

${ }^{4}$ My Story-Thinking: Cultural Meditations, NY: Nova Science, 2011, freely develops story thinking.
} 
and story-expressive, we all cherish and appreciate our thinking, so much so that our love of thinking bursts out singing music. Living is joy, and joy sings. Living thinks, and thinking in self-joy inevitably sings music as thinking.

Our thinking sings beautifully into music, as our singing beautifies our thinking, all irrelevant to ugly violence. Violent thinking and thinking in violence are forever out of line with the beautiful dignity of thinking as music. Music is made sensible by thinking, as thinking is ennobled and enriched by music. Music and thinking go back and forth in such a way as this to compose a delightful unity called "music thinking".

"Being human thinks, but how is being human sings music?" Being humanly alive is to be conscious of pulsating in rhythm day in and day out. Being conscious is to think. Pulsation in rhythm is music alive. And so, being alive as human is to engage music thinking. Being alive bodily sings music, as the heart beats, the blood circulates, and the lungs expand to breathe in, and then contract to breathe out. Heartbeats, blood-circulation, and lung-breathing in rhythm are all music singing to body-throb and story-express. Being humanly alive is music thinking that comprehensively body-thinks, concrete-thinks, and story-thinks.

China is unique in the world because of its inherent beauty ubiquitously musical that sings even the very shape of each character that begins to compose and chant literary expression musical. This written music is never as indifferent signs of alphabet that indifferently indicate statements, as in the West and elsewhere. The shapely music of characters writes out inevitably into singing "calligraphy" that is the music of singing art itself. Calligraphy is beautiful-writing that is a mere decoration in the West, but quite otherwise in China.

Can you imagine the "history of Chinese calligraphy" and "professors of Chinese calligraphy" routinely existing in Chinese universities all over, all taken for granted in China? Calligraphy is just an occasional hobby indulged by private oddities in the West. There is no such "calligraphy" as independent music in the West. Music thinking is serious and unique to Chinese culture, in all its various for (Wu, 2010) ${ }^{5} \mathrm{~ms}$, written and sung.

\section{Time Logic as Reverence and "Wu Wei” (No Do)}

Now, while appreciating the four thinking-modes above in China, I suddenly awaken to a realization. These four modes of thinking—body, concrete, story, and music_amount to showing how we are making sense of things, by moving back and forth among them. "Making sense" engages in logic. "Moving back and forth" is a process in time. Thus the four thinking-modes have been describing "time logic", in China (Wu, 2018b). ${ }^{6}$ Time logic is alive and constantly on the move, never staying as categorical.

“What is time logic?” As I think, so I say. As I say, so I act. And so, as I think, so I act. As I think and say, "I promise", I act the promising. Thinking modes are acting modes. The way I think is the way I act. These deeds take time to perform. And so, time logic is think-logic, say-logic, and act-logic. All such logic manifold involves grateful joy for myself. And so, time logic is joy-logic as music thinking that composes myself, human and alive. Time logic is my relentless and tenacious process of making sense in joy, in the four thinking-modes described above.

These four thinking-modes_-body, concrete, story, music — are the human modes of acting on things and reacting to things. Thus thinking-modes are acting-modes. We personally and subjectively reach out in these life-modes, and receive in these modes the objective impacts from outside. Being humanly alive consists in

\footnotetext{
${ }^{5}$ I developed reasons for why music thinking is necessary, in my Chinese Wisdom Alive: Vignettes of Life-Thinking, NY: Nova Science, 2010. I wish the book sings, though.

${ }^{6}$ I freely developed time logic in my Time Logic: Inter-Cultural Meditations, Houston, TX: Studium Press, 2018.
} 
such inter-responses with what surrounds us. We exert influences onto our environment, while we suffer impacts from our environment.

Our spontaneity in such inter-responses spells "wu wei, no-do". Our actions and reactions manifest reverence for all existence. Wu wei and reverence are our twin aspects of time logic. "Our time logic in the four thinking-modes as acting-modes inter-responding with the environment” spells our humanity alive. Time logic thus makes sense of humanity. Time logic is the logic alive of being human alive. Such time logic has its twin aspects, reverence and wu wei.

First, reverence cherishes all things. Such reverence is our life-obligation to all things, including the sudden and rude onslaught of devastating storms. We remain obligated to hold any and all things in reverence, on pain of devastations of the environment that result in our own deaths. Cherishing reverence of all things is our obligation that makes us thrive with our surrounding environment.

Dr. Albert Schweitzer merely crafted and proposed this crucial phrase, "reverence for existence", perhaps without realizing the enormous implications for lives and stunning repercussions to the environment, of this simple phrase. Our lack of all-reverence has already been harvesting worldwide pollutions at enormous prices all around all over. Such is how serious is our life-obligation to hold all things in reverence. Ironically, we all know what "reverence" means while we are in a serious need to be educated by our own enormous devastations of the environment by our own lack of reverence to all beings in Mother Nature.

"Does Chinese culture have reverence for nature?” O, Yes! Chinese culture is filled with Ecopiety aplenty. We are "small body" inside nature as "big body" (Mencius 6A15). It is common sense in all China that Heaven is our Father, Earth is our Mother, and humanity is their child, and they form a three-in-one family of the universe. This sense of the cosmos as a tight-knit family is vividly brought out by Chang Tsai in his "Western Inscription"7 where all things are sisters and brothers in the universe-family.

Secondly, you ask, "But then, what is wu wei no-do?” Sadly, we do not know how essential to our living it is. We do not even know what it is. We had better be careful. Time logic is the process personal and alive of double negations continuous that is wu wei. Double negations continue to negate into strong affirmations. Broken bones (negation-one) healed (negation-two) are now stronger (affirmations).

Chinese culture calls such double negations, "wu wei, no-do" that is neither "do" (negation-one) nor "not do" (negation-two). But then, the usual logical alternatives of "do" and "not do" in the West are exhausted. Wu wei cannot be logically explained. Here are some concrete incidents that are ready to story-tell wu wei, quite easily and quite simply, as the concrete is raw presence, easy and simple.

“Time for nap, Tommy my darling”, Mom calls. “O, No! No! No! No nap!” "Nap” is an utmost atrocious "dirty word" for Tommy. What can Mom do? Mom cannot grab Tommy by force and throw into his bed, to start World War Three. Mom must reject “do"; Mom must do negation-one. But then, Mom cannot just let Tommy go, either. His ferocious rejection tells of how tired he is, and he would at once get hurt. Mom must also reject "not do"; Mom must do rejection-two.

And so, spontaneously, Mom in her loving concern says, "OK, Tommy. No nap for you this time. Come here and sit beside your bed. Mom will tell you your favorite stories. But don’t sleep, OK?” Now Tommy can buy such a delicious offer. Tommy nods and comes silently to sit beside his bed. Now Mom can begin, very slowly, “Once-upon-a-time, very-very-long-time-ago, there-was-a-wicked-witch”.

\footnotetext{
${ }^{7}$ On “西銘” by 張載, see 陳榮捷, 中國哲學文獻選編（下），台北巨流圖書公司，民82, pp. 619-621.
} 
Before Mom's beginning sentence is over, Tommy just hits his pillow, sound asleep. Tommy happily takes a nap he so much needs, and Mom would now softly cover Tommy with his favorite blanket, and steals herself away in utter silence. "No-do" in sheer love has been performed, negating "do", negating "not do". "No do" that exhausts logical alternatives of "do" and "not do" and is so logically impossible, is actually so simple and routine in the concrete, as told in the above story. We cannot get over this story at all.

Mom's wu wei softly allows Tommy to reject nap, thereby paradoxically unites sleep rejected and sleep needed-into fulfilling Tommy himself. After all, it is all Tommy's desire to self-fulfillment that both rejected sleep he hates and fell into sleep he needs. Mom's wu wei both allows his rejection of sleep and soothes him into sleep he hates and needs. No wonder Tommy forever loves Mom even though he hates to guts what Mom says! We cannot help but smile at this attractive situation of wu wei.

Mom's wu wei softly allows Tommy to satisfy his intimate immediacy of desire to appear as "Tommy" himself. $W u$ wei objectifies the objects as objects in all their natural subjectivity as objects themselves. For the sake of objectivity, the scientific West simply suppresses all subjectivities to destroy all subjectivities. In contrast, Chinese soft wu wei allows the appearance of objectivity of things in all their inherent subjectivity. Self-forgetting wu wei achieves the self self-fulfilled, naturally, self-abandoned.

Tommy is still sound asleep, satisfying his need of sleep. Tommy's contradiction of hating the sleep he needs is now soothed away into self-consistency in his dreamless sleep so deep, thanks to Mom's wu wei. Mom's Chinese wu wei is a sight to behold, as Haydn's string quartets in the West are chanting wu-wei way, moving without moving, soothing without ceasing.

In reverence, I must repeatedly chant all their subjectivities in East and West, never desiring to hug them both for my private sake. We must then say that, in the end, it is Mom's wu wei (in love) that induces Tommy into loving Mom. Wu wei is all-powerful without power, quite invincible as it is all-victorious. Wow! All accolades go quite naturally to wu wei!

Such motherly wu wei did actually and repeatedly happen in the recent international arena. Two actual incidents at least can be cited. To begin, in the period not too many days before today, an obscure Harvard professor suddenly proposed out of nowhere (mentioning no source) "soft power" that yields, accommodates, and contains, in place of "hard power" of raw aggression and brutal oppression.

Of course, the American government has never accepted such a strange idea as "soft power" (power always powerfully suppresses and never yields), much less adopting it. He then retreated into a combination of soft power with hard power, and then, soon afterward, disappeared into nowhere. No one hears about such strange "soft power" today anywhere in the West.

Furthermore, his sudden appearance and disappearance of "soft power" in the West is noticed as precisely the wu wei in China, which is never sudden but has constantly been touted and routinely practiced since time immemorial in China. Such soft power of wu wei is actually practiced by China even today. Just a few decades ago, Japan suddenly, without forewarning, came over to China and brutally tried so hard to conquer China. Japan started its brutalities at major cities such as Nanking, and then inch by inch steadily incurred into Chinese inland. People in China suffered enormously.

In response, China neither did nothing nor aggressively attacked Japanese inland. The vast China simply continued to contain Japanese brutalities. Such Chinese practice of soft power of wu wei finally drained and tired out Japan completely. Japan capitulated soon. Japan had no choice but to retreat and pay apologies to China. China graciously accepted Japan. China’s soft power of wu wei has softly conquered Japan's hard power 
of aggression. "Do wu wei no-do, and nothing is not done”, says Lao Tzu 37, nonchalantly to characterize the usual way, Tao, of things.

Actually, we need not go far at all. All our debates so far above and beyond with the logical analysts have also been routinely practicing no-do of wu wei, denying their contentions (negation-one) to actually fulfill their ultimate goals (negation-two), and ours. We fulfilled observant objectivity of the logical analyst by keeping subjectivity in self-forgetting in body thinking.

We abstracted (negation-two) from abstraction (negation-one) to fulfill concrete thinking. Storytelling does not argue (negation-one) but guides argument in a new direction (negation-two), to fulfill story thinking. Music not arguing (negation-one) chants to fulfill argument (negation-two) in music thinking. Wu wei sings music thinking in joy sonorous without ceasing.

It is thus that the "no do" of Chinese wu wei is the summit beauty that sonorously fulfills all four thinking-modes in China. Wu wei is the time logic so dynamic on the musical move. As such, time logic in its "no do" on the go, continues joyously enabling and empowering all four thinking-modes that are typical of Chinese culture. All these four thinking-modes display time logic. Time logic on its part binds all these four thinking-modes, with its "no do wu wei".

Time logic is thus totally concrete beyond the standard set logic of the West. Chinese culture in all its grandeur of bodily and concrete story-thinking in musical persuasion is completely manifest alive and dynamic, in radical contrast to neat logical analysis of the West, all completely set and settled. Dynamic time logic so alive of China is in radical contrast to logical analysis set and settled of the West.

Now, here is another story that is no less actual and concrete. I happened to meet with a casual unassuming fellow, perhaps in his early fifties. He said he no longer goes to that church, either. I asked what his name is. He said his name is "Jesus". That shocked me awake. Have I been dreaming? And then, I realized how each common and casual person I see in neighborhood is a Jesus to whom I naturally owe care and service, as I owe care to my own self.

Now if Jesus is a God-man, the Second Commandment to love my neighbor as myself is (a simple extension of) the First Grand Commandment to love God with all my mud, heart, and soul. Love and reverence of all existence proposed by Albert Schweitzer the medical Bach-expert is no joke. No loving reverence heartfelt is the great crime human and beyond, punishable by death.

This conclusion irresistibly follows from surveying the Chinese culture in all its four thinking-modes as done above. Confucius completely agrees. Our Confucius in utmost reverence passionately envisioned such universal love of all brethren within Four Seas (Analects 12/5), ${ }^{8}$ and assiduously toiled after it all his life in sheer joy, even forgetting meals and forgetting his old age about to arrive (7/19).

We can never escape this life-obligation in joyous love of Confucius and Jesus, heartfelt. Very few people since they have been envisioning this life-joy of obligation, much less actually performing it. Humane service is an inescapable joy-duty of being human. We sigh and we strive after serving our fellow beings day and day out. This caring service is the essence of Chinese culture, no ifs and no buts.

\section{Three: Interculture}

While touting the grandeur of Chinese culture as above, I keep reminding myself of an absolute fact, if

\footnotetext{
8 This Confucian ideal is well expressed by his senior disciple in the Analects 12/5.
} 
there is anything absolute in the fact. It is that the essence of humanity is togetherness (Wu, 1998). Human lifeworld as intrinsically together implicates two important points; one is negative, and another is positive. Negatively, we human persons should not pretend to be "better than you" or "me alone". And positively, we humanity should gather to inter-learn to inter-enrich in interculture.

First, negatively, touting the grandeur of Chinese culture should never imply that Chinese culture in the East is better than American culture in the West, as the West used to claim itself better than the East until quite recent days. Kipling of the West famously intoned, "Oh, East is East, and West is West, and never the twain shalt meet" (1940, p. 233). Kipling is here trying to correct "we are better" by "me alone", which is another wrong. Kipling of the West sadly stays in the negative.

And so, positively in response to Kipling, we must intone back, saying, "Oh, East is East, and West is West, ever the twin should meet" to inter-learn to inter-enrich in interculture. As there is the grandeur of Chinese culture in the East, so there is the glory that is the West. As China has time logic dynamic, on the go among the four vibrant thinking-modes, so America has analytical logic neat and clear, set and classifying. East and West are both excellent in their own different ways, and both need to gather together to inter-complement one with the other. Difference should never inter-conflict.

In fact, only in contrast with the West does Chinese culture stand out in all its grandeur, as all explications of Chinese culture above have been conducted in debates against Western logical analyticity. By the same token, "me alone" of the West is now to be rescued from its idle vain solitude by standing out against the foil of Chinese culture of the East.

The concrete China shines in all its grandeur by standing-out existing-ek-histemi-against the background of the glory of American clarity. Grandiose time logic must be meditated on in the world of interculture, to manifest itself as true time logic (Wu, 2018b). ${ }^{9}$ After all, China tends to become as subtle as to turn vague. America on its part tends to turn as abstract as to be empty of its content.

Kant says that intuitions without thought are blind, and thought without intuitions is empty (Kant, 1999). ${ }^{10}$ To borrow Kant to our purpose, we say that China without America risks tending to be vague, as America without China would turn abstract and empty. Each must come home to the different other to fulfill itself. To go out of one's home is itself to come home back to one's own self. All this movement of going out and coming back home is called "interculture", quite essential to human togetherness.

\section{Conclusion}

In all, we together must claim this important claim. No identical twins are identical, ever. By nature, we are all different. Differences are for inter-complementation, never for inter-conflict and competition, given the fact that we are essentially together, and togetherness implicates inter-enrichment, never inter-butchery to perish away. Differences alive implicate delightful interculture. As togetherness is the essence of humanity, so interculture is the goal of togetherness. We in all our differences live for our identical interculture. Loss of interculture loses our very "self” of humanity.

This grandiose interculture brings us back to ourselves who have been doing interculture as we have had Chinese thinking-modes debate with Western thinking-modes. Performing interculture this way, this modest essay has touted, against glorious logical analysis of the West, the Chinese culture in all its grandeur of the four

\footnotetext{
9 I did so in my Time Logic: Inter-Cultural Meditations, Houston, TX: Studium Press, 2018.

${ }^{10}$ Immanuel Kant, The Critique of Pure Reason, B75 = A51.
} 
thinking-modes_-bodily and concrete, storytelling and musical—that together display actual time logic with subtle wu wei, all over the lifeworld, personal so intimate and cosmic so vast.

Thus to explicate Chinese culture against the backdrop of the West, such explication of Chinese culture itself has performed interculture. Interculture should be thoroughly concrete and specific, never to play in generalities. Playing with theoretical generalities here would completely fail to practice genuine interculture between East and West, between China and America.

There exists no methodological introduction to interculture before practicing interculture but not doing it yet. The introduction to interculture is itself its practice. This point is so important that it cannot be stressed too much. Interculture is thoroughly concrete, practical, and specific. To explicate the specific Chinese culture is to already perform interculture.

\section{References}

Huang, Y. (Ed.). (2009). Rorty, pragmatism, and Confucianism. Albany: State University of New York Press. Kipling, R. (1940). Rudyard Kipling's verse: Definitive edition (1891). Garden City, NY: Doubleday and Co. Kant, I. (1999). The critique of pure reason. Cambridge: Cambridge University Press.

Wu, K.-M. (1997). On Chinese body thinking: A cultural hermeneutic. Leiden: Brill.

Wu, K.-M. (1998). On the "logic” of togetherness: A cultural hermeneutic. Leiden: Brill.

Wu, K.-M. (2010). Chinese wisdom alive: Vignettes of life-thinking. NY: Nova Science.

Wu, K.-M. (2011). Story-thinking: Cultural meditations. NY: Nova Science.

Wu, K.-M. (2018a). Concrete thinking story-embodied as joy. Houston, TX: Studium Press.

Wu, K.-M. (2018b). Time logic: Inter-cultural meditations. Houston, TX: Studium Press. 